\title{
Author Correction: COVAN is the new HIVAN: the re-emergence of collapsing glomerulopathy with COVID-19
}

Juan Carlos Q. Velez (i), Tiffany Caza and Christopher P. Larsen

Nature Reviews Nephrology (2020) https://doi.org/10.1038/s41581-020-0332-3 Published online 04 August 2020

In the version of this article that was originally published online, there was a typographical error in the first name of the last author. This error has been corrected in the HTML and PDF versions of the manuscript.

https://doi.org/10.1038/s41581-020-00341-y I Published online 11 August 2020

() Springer Nature Limited 2020 